\title{
Research on childhood sexuality: Limitations and recommendations
}

\section{La investigación sobre sexualidad infantil: limitaciones y recomendaciones}

\author{
Eva González Ortega \\ Universidad de Salamanca \\ (Rec: marzo de 2020 - Acept: mayo de 2020)
}

\begin{abstract}
Children may display behaviours and have feelings of a sexual nature. However, due to the paucity of research, society often fails to acknowledge developmentally appropriate sexual experiences in childhood, and there is no consensus on which behaviours are normative. The purpose of this article is to review empirical evidence on the sexuality of children up to 12 years old. Specifically, the article aims to describe the main conclusions of studies, as well as to analyse the knowledge gaps, the methodological shortcomings, and the resulting recommendations for future research. According to the findings, studies should pay more attention to thoughts and feelings related to sexuality, the children's perspective; normative, healthy sexual expressions; and the relevant sexual socialization factors. Both direct and indirect methods, quantitative and qualitative techniques, should be combined to enhance the richness and validity of findings. The article also presents ethical tips. In conclusion, there is a need to further examine childhood sexuality from a comprehensive and ecological approach that provides an empirical basis for the development of interventions in children's sexual health.
\end{abstract}

Key words: Childhood, sexuality, review, methodology, ethics.

\section{Resumen}

Los niños pueden tener comportamientos y sentimientos de naturaleza sexual. Sin embargo, dada la escasa investigación científica, la sociedad a menudo no reconoce las experiencias propias del desarrollo sexual infantil, y no hay consenso sobre qué conductas son normativas. Por ello, el objetivo de este artículo es aportar una revisión de las evidencias empíricas disponibles sobre la sexualidad de los niños de hasta 12 años. Concretamente, se pretende describir las principales conclusiones alcanzadas en este campo, y analizar las lagunas de conocimiento y limitaciones metodológicas existentes, con las consiguientes sugerencias para futuras investigaciones. Los resultados indican que debe prestarse más atención a las cogniciones y sentimientos relacionados con la sexualidad, la perspectiva de los niños, las manifestaciones sexuales saludables y normativas, y los factores de socialización sexual relevantes. Se aconseja combinar métodos directos e indirectos, así como técnicas cuantitativas y cualitativas para una mayor riqueza y validez de los hallazgos. También se aportan consideraciones éticas. En conclusión, es necesario profundizar en la investigación de la sexualidad infantil desde una perspectiva integradora y ecológica que aporte una base empírica para el desarrollo de intervenciones en salud sexual infantil.

Palabras claves: Infancia, sexualidad, revisión, metodología, ética. 


\section{Introduction}

According to the World Health Organization (WHO, 2006), sexuality is "a central aspect of being human and encompasses sex, gender identities and roles, sexual orientation, eroticism, pleasure, intimacy, and reproduction." (p. 5). It is a lifelong process that begins at conception and continues through all stages of development, from infancy to the elderly. Therefore, children are also sexual beings.

Consistently, the scientific literature that has addressed childhood sexuality agrees that the sexual experiences of prepubertal children are broad and diverse. The entire range of possible expressions, however, may be grouped into various categories. López (2005) proposes an attractive frame of reference that focuses on the underlying needs and motivations. The need to know and interpret (motivation for curiosity) promotes exploratory behaviours of the body, observation of the sexual behaviours of others, sexual theories, questions about sexual issues and the like. The need for play and social learning (motivation for imitation and play) encourages imitation of sexual behaviours and attitudes, participation in sexual games, among others. Finally, the need to obtain sexual pleasure is present in self-stimulation behaviours such as child masturbation (sexual motivation).

Even though the interest of researchers in childhood sexuality has grown in the last two decades, it has not been as fast and intensively as it should have. There is "solid coverage of sexuality during adolescence and throughout adulthood, but scant attention to this topic during any of the prepubescent phases (...) studies of adolescent sexual behaviour does not begin assessing participants until age 12 or later" (Wurtele \& Kenny, 2011, p. 1). There are several reasons why this gap stands out relative to other research on human sexuality and childhood development (De Graaf \& Rademakers, 2011; López, 2014). First, most research has focused on sexual behaviour problems (e.g., Allen, 2017) or sexual abuse, thus considering children's sexual behaviour as either part of the abuse or a consequence of it. Funding agencies and ethics committees have been reluctant to support studies, and researchers have often encountered resistance from parents and teachers to consent for the participation of children in studies. Also, the limitations of children (regarding memory, language, social skills, among others) reduce the range of methods that used to obtain reliable and valid results.

This paucity of research has led to some negative consequences (Bancroft, 2003; De Graaf \& Rademakers, 2006). Families, professionals and society often fail to acknowledge that children may have healthy and developmentally appropriate sexual experiences and they consequently tend to interpret many children's sexual behaviours and feelings as atypical, harmful, abusive or as a sign of sexual abuse. Also, the scientific and professional community has not yet reached consensus on which childhood sexual behaviours are normative and healthy and which are problematic or abusive. Thus, it becomes difficult to detect sexual behaviour problems and sexual abuse while guaranteeing children's right to display and enjoy healthy and age-appropriate sexual behaviours. Moreover, precise and evidence-based guidelines on how to educate or intervene in this respect are still lacking.

Therefore, this article has three main objectives:
- Describe the main findings and conclusions of studies in this field.

- Analyse the gaps in knowledge and the existing methodological shortcomings in the literature.

- Present the resulting suggestions for future studies, including relevant ethical tips, and their positive implications for research and practice.

\section{Method}

The study used literature from the WorldCat catalogue and other databases provided by the University of Salamanca (e.g., PsychINFO, Medline, ERIC, Academic Search) by using variations of relevant keywords (e.g., childhood, children, sexuality, normative sexual development, sexual behaviour, sexual activity, sexual knowledge) both in English and Spanish. Also, it used reference lists of selected publications. Inclusion and exclusion criteria considered for the selection of publications were:

(a) Empirical research, therefore excluding theoretical and practical reflection.

(b) Focus on the healthy, normative sexual experiences, thus excluding literature primarily interested in sexual behaviour problems and sexual abuse (as already noted, these issues have extensively been addressed and reviewed).

(c) Focus on either sexual behaviours (solitary and interpersonal), cognitions or feelings (e.g. knowledge, attitudes, fantasies, excitement, attraction), consistently with the broad definition of childhood sexuality assumed by prior reviews (e.g., De Graaf \& Rademakers 2011; Wurtele \& Kenny, 2011) and the WHO (2006).

(d) Focus on prepubertal children from 0 to 12 years old, thus excluding adolescents.

(e) Studies carried out in the last two decades, that is, from 2000 to date.

(f) Studies conducted in Western societies, including Western Europe, North America, Australia, or New Zealand, with particular attention to Spain.

(g) Studies with a psychological approach versus philosophical, anthropological, biological, sociological, etc.

(h) Studies disseminated in scientific journals, books or doctoral theses.

First, the study checks the title and abstract. In the event of uncertainty, it checks the full text, as well as the eligibility of the publication.

\section{Results}

The result consists of 23 studies (marked with an asterisk in the Reference section) published in 21 articles and two book chapters. Following previous reviews (Bancroft, 2003; De Graaf \& Rademakers, 2006, 2011; Lamb \& Plocha, 2014), the observed evidence shows that children's sexual behaviour may be either solitary (genital touching or stimulation) or interpersonal (e.g., touching other person genitals, looking at nude people, showing genitals to other people). The latter is more common, although a remarkable portion of children displays both behaviours (e.g., López, Del Campo, \& Guijo, 2002) and there are substantial individual differences. Some children may show no interest in sexuality at all, whereas other children may be highly interested. 
Fortunately, interpersonal sexual experiences are generally voluntary (i.e., non-coercive) and involve another child of approximately the same age. Sexual behaviours that are similar to adult sexuality (e.g., oral-genital contact) represented a meagre portion (1-2\%) of non-abused children (e.g., Larsson \& Svedin, 2002a), but are more common among victims of sexual abuse (e.g., Friedrich et al., 2001). Nonetheless, unusual sexual behaviours are not necessarily problematic.

Regarding children's sexual thoughts and feelings, the scarce data available indicate that the most frequent reasons to engage in sexual experiences are curiosity and physical pleasure (Bancroft, Herbenick \& Reynolds, 2003; López et al., 2002). During middle childhood (8-9 years), most children can describe how it feels to be in love (Rademakers, Laan \& Straver, 2000). Feelings of sexual arousal, sexual attraction, and sexual fantasies are on average first experienced at the end of childhood, with boys experiencing them at an earlier age (Reynolds, Herbenick \& Bancroft, 2003).

Fortunately, feelings accompanying sexual behaviours are usually positive (e.g., excitement). However, children may also have negative feelings (e.g., anxiety, guilt) often experienced when sexual interactions involve pressure or someone who is not a same-aged friend (De Graaf \& Rademakers, 2006). As regards cognitions, knowledge of gender identity, genital differences, and sexual body parts increases during preschool years, whereas knowledge of reproduction and adult sexual behaviour increases during middle childhood (BrilleslijperKater \& Baartman, 2000).

Doubtlessly, children's sexual expressions vary across age groups due to developmental processes (Wurtele \& Kenny, 2011) at cognitive, social and emotional levels. Concretely, age changes in children's sexual behaviour and feelings appear to follow four different developmental phases (see Table 1): infancy and toddlerhood (birth to 2 years), early childhood (3-6 years), early elementary school children (6-9 years) and early adolescence (9-12 years). Nonetheless, "any demarcation of specific age categories is somewhat arbitrary, and common behaviours overlap considerably (...) there is substantial variability between children even of the same age. Thus, the age groups should not be seen as rigid dividing lines" (Wurtele \& Kenny, 2011, p. 3)

Table 1. Sexual manifestations displayed by some children, according to age group

\begin{tabular}{|c|c|}
\hline Age group & Sexual behaviours, cognitions and feelings \\
\hline $0-2$ years & $\begin{array}{l}\text { Spontaneous, reflexive sexual response (erection, lubrication) } \\
\text { Enjoyment of touch and nudity } \\
\text { Exploration of own body, including genitals } \\
\text { Curiosity about other people's genitals (touching, looking at, naming them) }\end{array}$ \\
\hline $3-5$ years & $\begin{array}{l}\text { Sex games with peers (usually touching or showing private parts) } \\
\text { Touching/rubbing of own genitals in public/private } \\
\text { Touching genitals/breasts of parents/siblings/peers } \\
\text { Voyeurism: looking at people when they are nude } \\
\text { Exhibitionism. E.g., showing genitals to adults or children } \\
\text { Awareness of differences between boys and girls } \\
\text { Questions about genitals, reproduction. } \\
\text { Use of slang terms for genital body parts } \\
\text { Acting out roles of mommy and daddy } \\
\text { Enjoyment of being a boy or girl, but not all children understand they will always be that gender. } \\
\text { Claiming to have "boyfriend" and "girlfriend" }\end{array}$ \\
\hline $6-9$ years & $\begin{array}{l}\text { Sex games with peers (e.g., truth or dare, playing doctor) } \\
\text { Self-stimulation of genitals } \\
\text { Looking at nude pictures; taking advantage of opportunity to look at others' genitals, buttocks, breasts } \\
\text { Exposure of genitals to others in private location } \\
\text { Questions about sexuality (e.g., genitals, intercourse, babies), talking about sex acts; drawing sexual parts } \\
\text { Use of "dirty" words for sexual behaviour, sexual or obscene jokes } \\
\text { Sense of gender constancy } \\
\text { Awareness of different forms of sexual orientation } \\
\text { Affectionate behaviour with peers (e.g., kissing and hugging, flirting) } \\
\text { Falling in love }\end{array}$ \\
\hline $10-12$ years & $\begin{array}{l}\text { Watching sexually explicit material } \\
\text { Fondling oneself or masturbating } \\
\text { Sexual fantasies } \\
\text { First feelings of sexual attraction } \\
\text { First sexual arousal or orgasm } \\
\text { More advanced knowledge about sexuality } \\
\text { Awareness of own and others' sexual orientation } \\
\text { Early sexual experiences, usually with the opposite sex (same-sex activity does not indicate homosexuality) }\end{array}$ \\
\hline
\end{tabular}

Note. Adapted from De Graaf \& Rademakers (2011) and Wurtele \& Kenny (2011). 
It is also worth mentioning that reports of childhood sexual behaviour decline with age when based on parents or teachers' observations (e.g., Miragoli, Camisasca, \& Di Blasio, 2017) but they increase when based on retrospective reports (e.g., Larsson \& Svedin, 2002b). This discrepancy may be partly explained by the fact that children's sexual behaviours become less observable as they grow older and learn that this kind of behaviour is "private" (De Graaf \& Rademakers, 2011).

Likewise, there are gender differences, although every single sexual expression may be displayed both by boys and girls (López, Fernández-Rouco, Carcedo, Kilani, \& Blázquez, 2010). Some findings (López, et al., 2002) suggest that boys are more likely to report pleasure-seeking, display most sexual behaviours (particularly masturbation) and remember feeling sexual arousal accompanying sexual behaviour. Instead, girls are more likely to report sexual play as a motivation for sexual behaviour, get involved in behaviours related to affect and interpersonal relationships (e.g., kissing, fondling, falling in love) and remember feeling guilt accompanying sexual behaviour.

\section{Limitations and gaps}

Unfortunately, this review supports that, although valuable, empirical evidence on normative childhood sexuality remains scarce, as previous reviews already pointed out (De Graaf \& Rademakers, 2011). As most findings come from the USA (e.g., Thigpen, 2009) and Nordic countries (e.g., Cacciatore, Ingman-Friberg, Lainiala, \& Apter, 2020), they cannot be generalized to other contexts. Cross-cultural differences encountered in children's sexual behaviour warn against direct extrapolation of results (Friedrich, Sandfort, Oostveen, \& Cohen-Kettenis, 2000; Kenny \& Wurtele, 2013; Larsson, Svedin, \& Friedrich, 2000).

In Spain, only two studies met the criteria for this review. The largest one used three sources of information (parents, teachers, and young adults/adolescents) to gather data about the sexual behaviours and feelings (motivations, sexual arousal, and guilt) of children up to 11 years old (López et al., 2002). In the context of a broad survey on health topics, the second study (Ballester \& Gil, 2006) analysed the reported sexual experiences (masturbation, intercourse, same-sex behaviour, pornography use) and sexual attitudes (towards the just-mentioned behaviours) of children aged 9 to 14 .

Note that sexual thoughts and feelings have been less frequently studied than sexual behaviour, as suggested by previous reviews (De Graaf \& Rademakers, 2006, 2011). Like most research, such as the Spanish studies (Ballester \& Gil, 2006; López et al., 2002) focus on the behavioural component of childhood sexuality, rather than on the cognitive and emotional ones. However, sexuality is "expressed in thoughts, fantasies, desires, beliefs, attitudes, values, behaviours, practices, roles and relationships" (WHO, 2006, p. 5). There is still a lack of evidence regarding sexual knowledge, motivations for sexual behaviour, feelings and thoughts elicited by sexual experiences, sexual arousal or attraction, sexual fantasies, and feelings of love. For example, what do children conceptualize as sexual? What are their beliefs regarding romantic relationships? How do they interpret different sexual behaviours (e.g., meaning, implications)? What are their attitudes towards masturbation, sexual double standards, sexual abuse, homosexuality and the like? What feelings, motivations and thoughts accompany their sexual experiences?
Furthermore, there is a lack of evidence on how children's socialization agents are associated with their sexual behaviours, thoughts and feelings. It is especially evident in Spain, where studies have only assessed children's gender and age as possible correlates of their sexual expressions (Ballester \& Gil, 2006; López et al., 2002). In general, studies have focused on family variables such as socioeconomic status, educational level, parent-child communication about sex, family stress/ violence, and family sexuality (e.g., Cale \& Lussier, 2017; Thigpen \& Fortenberry, 2009). Also, they have focused on teachers' responses to childhood sexual behaviour (e.g., Kaeser, DiSalvo, \& Moglia, 2000), but rarely exploring peers, media, or internet variables. Moreover, many of these studies provide descriptive data on contextual factors but do not test the existence of significant associations with children's sexual-related variables (e.g., Kastbom et al., 2012).

It is also important to warn about the main methodological shortcomings of the studies conducted in this area. First, most research comes from surveys with close-ended questions or standardized scales, especially, the Child Sexual Behaviour Inventory by Friedrich (1997) or some adaptation (e.g. Sandnabba, Santtila, Wanäs, \& Krook, 2003; Thigpen, 2009). Authors rarely use qualitative methods such as interviews, diaries or focus groups (Brilleslijper-Kater \& Baartman, 2000; Halstead \& Waite, 2001; Kaeser, DiSalvo, \& Moglia, 2000; Rademakers et al., 2000; Schuhrke, 2000). They indicate that it is more time-consuming and expensive, and parents and teachers are reluctant to let children talk openly and face-to-face about this sensitive issue (De Graaf \& Rademakers, 2006). Likewise, only a few studies opt for a mixed-method approach (e.g., Balter, Van Rhijn, \& Davies, 2016).

Second, few studies use direct methods (Ballester \& Gil, 2006; Brilleslijper-Kater \& Baartman, 2000; Halstead \& Waite, 2001; Rademakers et al., 2000) although "it is often assumed that interviews or surveys of children provide the most valid information about child sexual behaviour" (O'Sullivan, 2003, p. 27). Instead, most research asks adolescents/adults about their memories (e.g., Bancroft et al. 2003; Larsson, \& Svedin, 2002b) or parents and teachers about what they have observed (e.g., Davies, Glaser, \& Kossoff, 2000; Sandfort \& Cohen-Kettenis, 2000). Retrospective reports predominantly use to obtain information on sexual behaviours during middle and late childhood. In contrast, the observation by intermediaries primarily collects data on sexuality during early childhood (De Graaf \& Rademakers, 2011). It is worth noting that most findings on children's thoughts and feelings regarding sexuality based on retrospective surveys applied to college or senior high school students (e.g., Bancroft et al., 2003; Larsson \& Svedin, 2002b; López et al., 2002; Reynolds et al., 2003). Therefore, they are likely to be affected by memory inaccuracies or distortions.

In Spain, López et al. (2002) used paper-and-pencil surveys with close-ended questions to collect data from participants (parents, teachers, adolescents and college students). They only conducted three focus groups with parents and teachers. Ballester and Gil (2006) directly questioned children about sexual issues, but through a small set of scales, yes/ no or multiple-choice survey questions. No interview was conducted in either of these studies. In both cases, moreover, non-representative sampling procedures were used to recruit small samples from only one or several regions of the country. 
Suggestions for future research work

Given the above-cited weaknesses in the literature, researchers should bear in mind the following suggestions for their future work.

As regards the focus of attention, and in line with previous reviews (Bancroft, 2003; De Graaf \& Rademakers, 2011), this review supports the need for more empirical evidence that sheds light on the range of sexual behaviours and feelings to be expected from non-abused children. More attention should be given to the variations by gender and age, as well as across and within cultures. Quoting Frayser (2003, p. 102), "to formulate and adequate definition of what is normal we have to look at the human population, not just the American population". It is necessary to have more detailed depictions of cognitions and emotions about sexuality(knowledge, motives, values, beliefs, attitudes, feelings of attraction, love, intimacy, and the like), as well as more in-depth knowledge of the factors that affect childhood sexual experiences from an ecological perspective (e.g. Simmons, 2014) with particular focus on the family and sociocultural context.

Regarding methodology, investigators should consider several suggestions. First, triangulation because every method "can be valuable, depending on the research questions and the ages of the children that are studied" (De Graaf \& Rademakers, 2011, p. 126). Concretely, it is advisable to use observational methods to study younger age groups, given that their disadvantages mainly apply to middle and late childhood, and to use retrospective methods to study older age groups, considering that their disadvantages apply to early childhood. When collecting retrospective reports, researchers should shorten the time lapse between participants' age and the period investigated (De Graaf \& Rademakers, 2011).

Second, the suggestion of direct methods because of their unique advantages, as they enable studying cognitions and emotions from the children's point of view (De Graaf \& Rademakers, 2011). Researchers should formulate questions and tasks that match children's developmental level, that is, by using age-appropriate words or including pictures. It is possible to interview children about sexual issues from the age of 2 if the questions are concrete. However, children aged 7 or more can answer more complex questions (e.g., about internal states) due to their increased language and cognitive capabilities (De Graaf \& Rademakers). There is "no minimum age at which children can begin expressing their views freely, nor does it limit the contexts in which children can express their views" (UNICEF, n.d.).

Third, the literature would benefit from the use of qualitative methods. Children's sexuality involves complex processes and diversity of biographies that may not be comprehensively understood by exclusively adopting a quantitative approach. Qualitative methods help to obtain more in-depth and detailed responses, to gain a context understanding, to minimize researcher biases by avoiding preconceived categories, and to illustrate and corroborate quantitative findings. Focus groups would help to study group norms and variations within the population. In contrast, interviews would be useful to elicit individual experiences, opinions, and feelings, as well as to address sensitive topics. Besides, surveys with open-ended questions could gather vast amounts of qualitative information from large samples. Their anonymity helps collect data on more sen- sitive issues, although they demand a certain level of literacy (Fargas-Malet, McSherry, Larking, \& Robinson, 2010).

Fourth, researchers should develop new tools for the assessment of sexual-related variables in children and test their psychometric properties to expand the limited number of data collection instruments available. These instruments should aim to overcome the developmental limitations of children (regarding memory, language and others) that threaten the reliability and validity of the results. There is a wide range of tools that have shown to be useful for research of children about sexuality or other sensitive topics (Fargas-Malet et al., 2010):

- Stimulus materials. Written prompts (e.g., sentence completion, unfinished stories) and feelings faces facilitate communication. Visual materials serve to clarify questions (e.g., visual vignettes to test whether the children distinguish between physical intimacy and sexual interaction).

- Asking children to make drawings serves as a trigger for memories, discussion, or self-reflection, and helps them organize their narratives.

- Participatory techniques facilitate active and enjoyable participation: free listings, card sorting (e.g., similarities/differences, the most/the least), rating of words, label generation; picture selection, storytelling, roleplaying and others. (Colucci, 2007).

Fifth, the recruitment of more substantial and more representative samples is suggested to enhance the generalizability of findings, and to better examine the portion of children who have specific experiences and feelings at a certain age (De Graaf \& Rademakers, 2011). The implementation of more longitudinal studies (e.g., Lussier, McCuish, Mathesius, Corrado, \& Nadeau, 2017) would also be beneficial to examine the causal determinants, medium/long-term outcomes and developmental processes of children's sexual behaviours, thoughts, and feelings.

Finally, ethical considerations are worth mentioning because of the perception of research on children's sexual development, and activity proves to be too sensitive and potentially harmful to children (Flanagan, 2012). One crucial recommendation in this regard is to be careful about privacy and confidentiality protection and obtain written informed consent from the legal guardians. Child participants must fully understand the informed assent forms and thus freely and honestly agree to participate. These forms must indicate that the instruments include sensitive questions about sexuality and emphasize that participants have the agency to decide what they say, and the right to leave any question unanswered or even to withdraw whenever and for whatever reason. A recommendation is to use the informed consent form templates developed by WHO- Research Ethics Review Committee (n.d.).

Also, researchers must pay attention to children's wellbeing and comfort before, during and after participation. Specifically, among other actions, researchers should (McCosker, Barnard, \& Gerber, 2001; Fargas-Malet et al., 2010):

- Ensure that the instrument administrator does not occupy a position of power to avoid the risk of the child's feeling coerced or vulnerable.

- Use a private, quiet and comfortable setting where a 
second trustworthy person is easily accessible to the child.

- Pay attention to rapport building and pose the least complicated and least sensitive questions at the beginning and the end.

- Neutrally ask questions, avoiding expressions of approval or disapproval and emphasizing that there are no right or wrong answers.

- Let the children use their own words to describe or explain their behaviour, thoughts, and feelings provided that they are not rude or offensive.

- Ensure that focus group rules are understood and respected (participants are not allowed to make fun of the others, be aggressive or rude, reveal intimate aspects of others.).

- Be aware of signs of impatience, annoyance, distress, or reluctance to answer questions and thus consider the need for taking breaks or terminating participation.

- Give the child time to express possible intense or negative emotions and, should they appear, show empathy and acceptance of these responses and provide a list of recommended counsellors.

- Contact the child several days after participation to check for possible forms of distress and need for counselling.

The WHO-ERC (n.d.) and the Ethical Research Involving Children -ERIC-project (n.d.) provide more detailed guidelines in this regard.

\section{Conclusions}

In summary, considering the gaps and shortcomings in the evidence available, this review emphasizes the need to: focus on the normative, healthy, age-appropriate sexual expressions and experiences, rather than on those that are problematic or abusive; pay attention not only to children's behaviours related to sexuality but to their thoughts and feelings as well; consider a broader range of sexual socialization agents (parents, teachers, peers, and media) that might help understand children's sexuality, thus going beyond sociodemographic factors; and use an interdisciplinary approach that draws not only on the theories of psychology but sociology, language, culture, education as well, in order to enrich the understanding of childhood sexuality (Gilbert \& Lamb, 2018).

A multi-method approach is recommended to enhance the richness, reliability and validity of findings. Researchers should use not only indirect methods (i.e., questioning adolescents/ adults about their recollections or parents/teachers about their observations) but also direct methods (i.e., questioning children). Thus, source triangulation would favour collecting more valid data while avoiding observer and memory distortions, as well as biases derived from the adult perspective. Most evidence as of to date allows concluding that children may display behaviour and have feelings that "adults would call sexual or that they would later remember as sexual" (De Graaf \& Rademakers, 2006, p. 16). Nonetheless, the validity of these conceptualizations and recollections is inevitably limited. The significant developmental changes that affect adults and post-pubescent minors (regarding sexual anatomy and physiology, sexual affects, cognitive abilities, among others) lead to reinterpretations of sexual behaviours and consequent difficulties in the understanding of the meaning given by chil- dren and the emotions that accompany them. Therefore, adult participants may mistakenly attribute sexual motivation to certain observed behaviours in children (O'Sullivan, 2003), especially when they resemble those of adults, while in other occasions they may refuse to consider certain behaviours as sexual due to the alleged "innocence" of children.

On top of quantitative methods (e.g., scales, close-ended survey questions) researchers should also use qualitative methods (e.g., open-ended survey questions, interviews, focus groups), as this methodological triangulation favours in-depth and detailed responses and better context understanding. The few studies that have addressed children's perceptions and representations of sexuality through direct methods and qualitative techniques (e.g., Rademakers et al., 2000) provide a useful reference for future studies in Spain.

The scientific community should bear in mind that considering the suggestions of this study would open many opportunities and horizons not only for science but also for awareness-raising, evaluation, education purposes. Namely, this research approach would enhance the acknowledgement of children's capacity for pleasurable and safe sexual experiences, as well as their right to enjoy them (WAS, 2014) by providing further proof of childhood sexual behaviours and feelings that are not abusive or problematic. It would also contribute to the development of the needed science-based statement of what constitutes normal sexual expression in childhood and the consequent establishment of a baseline for assessment of the sexual behaviour that should be cause for intervention or concern.

More empirical evidence on childhood sexuality would drive the development of sex education programs and resources that are comprehensive, age-appropriate, scientifically accurate and grounded in a positive approach to sexuality (WAS, 2014), which are notably lacking for Infant and Primary school education. Likewise, it would provide policymakers and professionals (e.g., psychologists, social workers, teachers, clinicians, lawyers) with a useful empirical framework on which to develop more appropriate and effective policies and guidelines to protect children's sexual wellbeing and rights.

A more in-depth study of children's sexual knowledge, thoughts and feelings across ages would foster an evidence-based discussion about the legal age for sexual consent. It would help to determine the age at which most children develop the cognitive and emotional capabilities that enable free and responsible consent for sexual activities. Similarly, studies on children's sexual experiences might indirectly help to increase and update the data available on the prevalence of child sexual abuse, due to the likely collection of reports of abusive experiences, either suspected, observed, or selfdisclosed.

Beyond these potential outcomes for theory and practice, "studying childhood sexuality is a perfectly valid scientific aim in itself" (Rademarkers, 2003, p. 284), and regardless of the sensitivity of the topic, research focused on children should not be avoided or shut down because of its difficulty (Flanagan, 2012). 


\section{References}

Allen, B. (2017). Children with Sexual Behaviour Problems: Clinical characteristics and relationships to child maltreatment. Child Psychiatry and Human Development, 48(2), 189-199.

*Ballester, R., \& Gil, M.D. (2006). La sexualidad en niños de 9 a 14 años [Sexuality in children 9-14 years old]. Psicothema, 18(1), 25-30.

*Balter, A. S., Van Rhijn, T. M., \& Davies, A. W. J. (2016). The development of sexuality in childhood in early learning settings: An exploration of early childhood educators' perceptions. The Canadian Journal of Human Sexuality, 25(1), 30-40.

Bancroft, J. (Ed.) (2003). Sexual development in childhood. Bloomington: Indiana University Press.

*Bancroft, J., Herbenick, D. L., \& Reynolds, M. A. (2003). Masturbation as a marker of sexual development. Two studies 50 years apart. In J. Bancroft (Ed.), Sexual development in childhood (pp.134-155). Bloomington, IN: Indiana University Press.

*Brilleslijper-Kater, S. N., \& Baartman, H. E. M. (2000). What do young children know about sex? Research on the sexual knowledge of children between the ages of 2 and 6 years. Child Abuse Review, 9(3), 166-182.

*Cacciatore, R. S.-M., Ingman-Friberg, S. M.-L., Lainiala, L. P., \& Apter, D. L. (2020). Verbal and behavioural expressions of child sexuality among 1-6 year-olds as observed by daycare professionals in Finland. Archives of Sexual Behaviour. DOI: https://doi-org. ezproxy.usal.es/10.1007/s10508-020-01694-y

Cale, J. \& Lussier, P. (2017). Sexual behaviour in preschool children in the context of intra-parental violence and sexual coercion. Criminal Behaviour and Mental Health, 27(2), 176-190.

Colucci, E. (2007). "Focus groups can be fun": The use of activity-oriented questions in focus group discussions. Qualitative Health Research, 17(10), 1422-1433.

*Davies, L. S., Glaser, D. y Kossoff, R. (2000). Children's sexual play and behaviour in pre-school settings: staff's perceptions, reports, and responses. Child Abuse and Neglect, 24(10), 1329-1343.

De Graaf, H., \& Rademakers, J. (2006). Sexual behaviour of prepubertal children. Journal of Psychology \& Human Sexuality, 18(1), 1-21.

De Graaf, H., \& Rademakers, J. (2011). The Psychological measurement of childhood sexual development in western societies: Methodological challenges. The Journal of Sex Research, 48 (2-3), 118-129.

Ethical Research Involving Children -ERIC (n.d). Ethical guidance. Retrieved from: http://childethics.com/ ethical-guidance/

Fargas-Malet, M., McSherry, D., Larking, E., \& Robinson, C. (2010). Research with children: Methodological issues and innovative techniques. Journal of Early Childhood Research, 8(2), 175-192.

Flanagan, P. (2012). Ethical review and reflexivity in research of children's sexuality. Sex Education: Sexuality, Society and Learning, 12(5), 535-544.

Frayser, S. G. (2003). Methodological aspects. General discussion. In J. Bancroft (Ed.), Sexual development in childhood (pp. 102). Bloomington: Indiana University Press.

Friedrich, W.N. (1997). Child Sexual Behaviour Inventory: Pro- fessional manual. Odessa, FL: Psychological Assessment Resources.

*Friedrich, W. N., Fisher, J., Dittner, C., Acton, R., Berliner, L., Butler, J., ... Wright J. (2001). Child Sexual Behaviour Inventory: Normative, psychiatric and sexual abuse comparisons. Child Maltreatment, 6, 37-49.

*Friedrich, W. N., Sandfort, T., Oostveen, J., \& Cohen-Kettenis, P. T. (2000). Cultural differences in sexual behaviour: 2-6 year-old Dutch and American children. Journal of Psychology \& Human Sexuality, 12(1-2), 117-129.

Gilbert, J. \& Lamb, S. (2018). Interdisciplinary Approaches to Sexual Development in Childhood and Adolescence. In S. Lamb and J. Gilbert (Eds.) The Cambridge Handbook of Sexual Development: Childhood and Adolescence (pp. 1-13). Cambridge University Press

*Halstead, J. M. \& Waite, S. (2001). "Living in different worlds": gender differences in the developing sexual values and attitudes of primary school children. Sex Education, 1(1), 59-76.

*Kaeser, F., DiSalvo, C., \& Moglia, R. (2000). Sexual behaviours of young children that occur in schools. Journal of Sex Education and Therapy, 25(4), 277-285.

*Kastbom, A., Larsson, I., \& Svedin, G. (2012). Parents' observations and reports on the sexual behaviour of 7 to 13 years old children. Reproductive System \& Sexual Disorders, 1(2), 1-6.

*Kenny, M. C. \& Wurtele, S. K. (2013). Child Sexual Behaviour Inventory: A comparison between Latino and normative samples of pre-schoolers. Journal of Sex Research, 50(5), 449-457.

Lamb, S., \& Plocha, A. (2014). Sexuality in childhood. In D.L. Tolman \& L.M. Diamond (Eds.), APA handbook of sexuality and psychology: Vol. 1. Person-based approaches (pp. 415-432). Washington, DC: American Psychological Association.

*Larsson, I., \& Svedin, C. G. (2002a). Teachers' and parents' reports on 3 to 6-year-old children's sexual behaviour. A comparison. Child Abuse \& Neglect, 26(3), 247-266.

*Larsson, I., \& Svedin, C. G. (2002b). Young adults' recollections of sexual behaviour and experiences in childhood. Archives of Sexual Behaviour, 31(3), 263-273.

*Larsson, I., Svedin, C. G., \& Friedrich, W. N. (2000). Differences and similarities in sexual behaviour among pre-schoolers in Sweden and USA. Nordic Journal of Psychiatry, 54(4), 251-257.

López, F. (2005). La educación sexual. Madrid: Biblioteca Nueva.

López, F. (2014). Los abusos sexuales a menores y otras formas de maltrato sexual. Madrid: Síntesis.

*López, F., Del Campo, A., \& Guijo, V. (2002). Prepuberal sexuality. European Journal of Medical Sexology: Sexologies, 11(42), 1-12.

López, F., Fernández-Rouco, N., Carcedo, R.J., Kilani, A., \& Blázquez, M. I. (2010). La evolución de la sexualidad prepuberal y adolescente: Diferencias en afectos y conductas entre varones y mujeres. Cuestiones de género: De la igualdad a la diferencia, 5, 165-184

Lussier, P., McCuish, E., Mathesius, J., Corrado, R., \& Nadeau, D. (2017). Developmental trajectories of child sexual behaviours on the path of sexual behavioural problems. Evidence from a prospective longitudi- 
nal study. Sexual Abuse: A Journal of Research and Treatment, 1-37.

McCosker, H., Barnard, A. \& Gerber, R. (2001). Undertaking sensitive research: Issues and strategies for meeting the safety needs of all participants' Forum: Qualitative Social Research, 2(1), 2-6.

*Miragoli, S., Camisasca, E., \& Di Blasio, P. (2017). Child sexual behaviours in school context: Age and gender differences. Journal of Child Sexual Abuse, 26(2), 213-231.

O'Sullivan, L. F. (2003). Methodological issues associated with studies of child sexual behaviour. In J. Bancroft (Ed.), Sexual development in childhood (p. 27). Bloomington, IN: Indiana University Press

Rademakers, J. (2003). Cross-cultural aspects. General discussion. In J. Bancroft (Ed.), Sexual development in childhood (pp. 284). Bloomington: Indiana University Press.

*Rademakers, J., Laan, M. y Straver, C. (2000). Studying children's sexuality from the child's perspective. Journal of Psychology \& Human Sexuality, 12(1-2), 49-60.

*Reynolds, M. A., Herbenick, D. L., \& Bancroft, J. (2003). The nature of childhood sexual experiences. Two studies 50 years apart. In J. Bancroft (Ed.), Sexual development in childhood (pp.134-155). Bloomington, IN: Indiana University Press.

*Sandfort, T. G. M. \& Cohen-Kettenis, P. T. (2000). Sexual behaviour in Dutch and Belgian children as observed by their mothers. Journal of Psychology \& Human sexuality, 12(1-2), 105-115.

*Sandnabba, N. K., Santtila, P., Wanäs, M., \& Krook, K. (2003). Age and gender specific sexual behaviours in children. Child Abuse \& Neglect, 27, 579-605.

*Schuhrke, B. (2000). Young children's curiosity about other people's genitals. Journal of Psychology \& Human Sexuality, 12(1-2), 27-48.

Simmons, K. (2014). Childhood sexual behaviour: An integrated developmental ecological assessment approach. Antioch University Dissertations \& Theses, 276.

*Thigpen, J. W. (2009). Early sexual behaviour in a sample of low-income, African American children. Journal of Sex Research, 46(1), 67-79.

Thigpen, J. W., \& Fortenberry, J. D. (2009). Understanding variation in normative childhood sexual behaviour: The significance of family context. Social Service Review, 83(3), 611-631.

UNICEF (n.d.). Fact sheet. The right to participation. Retrieved from: http://www.unicef.org/crc/files/Right-toParticipation.pdf

WAS (2014). WAS Declaration of Sexual Rights. World Association for Sexual Health

WHO (2006) Defining sexual health. Report of a technical consultation on sexual health, 28-31 January 2002. Geneva: World Health Organization.

WHO Research Ethics Review Committee - ERC (n.d). Informed consent form templates. Retrieved from: https://www.who.int/ethics/review-committee/ informed_consent/en/

Wurtele, S. K., \& Kenny, M. C. (2011). Normative sexuality development in childhood: Implications for developmental guidance and prevention of childhood sexual abuse. Counseling and Human Development, 43(9), 1-24.
Declaration of interest statement: No potential conflict of interest was reported by the authors. 